\title{
Hyperglycaemia-induced impairment of endothelium-dependent vasorelaxation in rat mesenteric arteries is mediated by intracellular methylglyoxal levels in a pathway dependent on oxidative stress
}

\author{
O. Brouwers • P. M. Niessen • G. Haenen • T. Miyata • \\ M. Brownlee • C. D. Stehouwer • J. G. De Mey • \\ C. G. Schalkwijk
}

Received: 4 December 2009 / Accepted: 23 December 2009 / Published online: 26 February 2010

(C) The Author(s) 2010. This article is published with open access at Springerlink.com

\begin{abstract}
Aims/hypothesis Impaired nitric oxide (NO)-dependent vasorelaxation plays a key role in the development of diabetic vascular complications. We investigated the effect of hyperglycaemia on impaired vasoreactivity and a putative role therein of the AGE precursor methylglyoxal. Methods The effects of high glucose and methylglyoxal on NO-dependent vasorelaxation in isolated rat mesenteric arteries from wild-type and transgenic glyoxalase (GLO)-I (also known as GLO1) rats, i.e. the enzyme detoxifying
\end{abstract}

Electronic supplementary material The online version of this article (doi:10.1007/s00125-010-1677-0) contains supplementary material, which is available to authorised users.

O. Brouwers · P. M. Niessen · C. D. Stehouwer •

C. G. Schalkwijk $(\bowtie)$

Department of Internal Medicine, University Hospital Maastricht, P. Debyelaan 25, P.O. Box 5800, 6202 AZ Maastricht, the Netherlands

e-mail: C.Schalkwijk@INTMED.unimaas.nl

G. Haenen · J. G. De Mey

Department of Pharmacology and Toxicology,

Maastricht University,

Maastricht, the Netherlands

T. Miyata

Centre of Translational and Advanced Research,

Tohoku University,

Sendai, Japan

M. Brownlee

International Center for Diabetic Complications Research,

Albert Einstein College of Medicine,

New York, NY, USA methylglyoxal, were recorded in a wire myograph. AGE formation of the major methylglyoxal-adduct 5-hydro-5methylimidazolone (MG-H1) was detected with an antibody against MG-H1 and quantified with ultra-performance liquid chromatography (tandem) mass spectrometry. Reactive oxygen species formation was measured with a 5-(and6)-chloromethyl-2'7'-dichlorodihydrofluorescein diacetate acetyl ester probe and by immunohistochemistry with an antibody against nitrotyrosine.

Results High glucose and methylglyoxal exposure of mesenteric arteries significantly reduced the efficacy of NO-dependent vasorelaxation $(p<0.05)$. This impairment was not observed in mesenteric arteries of GLO-I transgenic rats indicating a specific intracellular methylglyoxal effect. The diabetes-induced impaired potency $\left(\mathrm{pD}_{2}\right)$ in mesenteric arteries of wild-type rats was significantly improved by GLO-I overexpression $(p<0.05)$. Methylglyoxal-modified albumin did not affect NO-dependent vasorelaxation, while under the same conditions the receptor for AGE ligand S100b did $(p<0.05)$. Methylglyoxal treatment of arteries increased intracellular staining of MG-H1 in endothelial cells and adventitia by fivefold accompanied by an eightfold increase in the oxidative stress marker nitrotyrosine. Antioxidant pre-incubation prevented methylglyoxal-induced impairment of vasoreactivity.

Conclusions/interpretation These data show that hyperglycaemia-induced impairment of endothelium-dependent vasorelaxation is mediated by increased intracellular methylglyoxal levels in a pathway dependent on oxidative stress.

Keywords AGE - Endothelium · Glycation · Microvascular disease $\cdot$ Oxidative stress $\cdot$ Rat 


\begin{tabular}{|c|c|}
\hline Abbreviations & \\
\hline CEL & $N^{\varepsilon}$-(Carboxyethyl)lysine \\
\hline $\mathrm{CM}-\mathrm{H}_{2} \mathrm{DCFDA}$ & $\begin{array}{l}\text { 5-(and-6)-Chloromethyl-2'7'- } \\
\text { dichlorodihydrofluorescein diacetate } \\
\text { acetyl ester }\end{array}$ \\
\hline CML & $N^{\varepsilon}$-(Carboxymethyl)lysine \\
\hline eNOS & Endothelial nitric oxide synthase \\
\hline GLO-I & Glyoxalase-I \\
\hline MG-H1 & 5-Hydro-5-methylimidazolone \\
\hline MTT & $\begin{array}{l}\text { 3-(4,5-Dimethylthiazol-2-yl)-2,5- } \\
\text { diphenyltetrazolium bromide }\end{array}$ \\
\hline NA & Numerical aperture \\
\hline NAC & $N$-Acetyl-L-cysteine \\
\hline NO & Nitric oxide \\
\hline RAGE & Receptor for AGE \\
\hline ROS & Reactive oxygen species \\
\hline SNP & Sodium nitroprusside \\
\hline UPLC-MSMS & $\begin{array}{l}\text { Ultra-performance liquid chromatogra } \\
\text { phy (tandem) mass spectrometry }\end{array}$ \\
\hline
\end{tabular}

\section{Introduction}

Diabetes mellitus is associated with an increased risk of cardiovascular disease [1]. Endothelial dysfunction is considered to be the primary cause in the pathogenesis of vascular disease in diabetes [1]. Although the mechanism whereby diabetes leads to endothelial dysfunction is incompletely understood, a common feature of endothelial dysfunction is a decreased bioavailability of endothelium-derived nitric oxide (NO) and, as a consequence, impaired endothelium-dependent vasorelaxation [1]. Several studies have demonstrated impaired endothelium-dependent vasorelaxation in diabetic patients $[2$, $3]$ and in animal models of diabetes $[4,5]$.

One hypothesis of how hyperglycaemia leads to endothelial dysfunction and vascular complications is the formation of AGEs [6]. AGEs are a heterogeneous family of non-enzymatically modified proteins formed by carbohydrates, which are increased in patients with diabetes [7-9]. The mechanisms by which AGEs contribute to vascular complications are multiple, including their interaction with the receptor for AGE (RAGE), the formation of cross-links in basal membranes and intracellular accumulation of glycated proteins [6]. Although it has been demonstrated that AGEs are associated with impaired endothelium-dependent vasorelaxation in type 2 diabetes [10] and can reduce endothelium-dependent vasorelaxation [11], it is not known which specific AGEs are the culprits or which pathways are involved.

It is now apparent that especially intracellular sugars and their derivatives can participate in glycation and AGE formation [12]. The reactive dicarbonyl methylglyoxal has received considerable attention as the most reactive AGE precursor in endothelial cells [13]. Methylglyoxal is formed non-enzymatically by dephosphorylation of triose phosphates and is efficiently catabolised to D-lactate by the glyoxalase (GLO) pathway, consisting of GLO-I, GLO-II and the co-factor glutathione [14]. Methylglyoxal primarily reacts with arginine residues to form the major adduct 5-hydro-5-methylimidazolone (MG-H1) and with lysine to form $N^{\varepsilon}$-(1-carboxyethyl)lysine (CEL) $[15,16]$. Plasma methylglyoxal levels are significantly increased in diabetic patients [17] and in endothelial cells by hyperglycaemia [18]. The importance of methylglyoxal and methylglyoxalderived AGEs for the development of diabetic vascular complications and hypertension has only recently been recognised. Recent studies have demonstrated that increased methylglyoxal-derived AGE levels in diabetic patients are associated with diabetic complications such as nephropathy [19] and retinopathy [20], and with diabetesrelated vascular disorders such as hypertension [21-25]. As a major precursor of AGE formation, methylglyoxal can influence multiple aspects of cellular biology in diabetes [26]. Methylglyoxal targets specific mitochondrial proteins accompanied by an increase in the formation of reactive oxygen species (ROS) [27]. Since ROS production by mitochondria is responsible for major mechanisms involved in diabetic complications, methylglyoxal-induced ROS production may be an initial event in the pathogenesis of vascular complications.

We hypothesised that accumulation of methylglyoxal can lead to endothelial dysfunction by ROS formation and therefore evaluated the effect of hyperglycaemia, methylglyoxal and methylglyoxal-modified albumin on endotheliumdependent NO-mediated vasorelaxation, a measure of endothelial function, and tested the involvement of oxidative stress therein.

\section{Methods}

Animals All animal studies were carried out in accordance with the Guide for the Care and Use of Laboratory Animals of the National Institutes of Health. All experiments involving rats were reviewed and approved by the Ethics Committee for animal care and use of Maastricht University, the Netherlands.

GLO-I (also known as GLO1) transgenic rats were obtained from T. Miyata [28]. Rat genomic DNA extracted from tail tissue was used to detect the transgene by PCR using specific primers for $G L O-I$ or pBsCAG-2 vector. Primers for cytomegalovirus enhancer, sense $\left(5^{\prime}\right.$-GTC GAC ATT GAT TAT TGA CTA G-3') and antisense (5'-CCA TAA GGT CAT GTA CTG-3'), amplified a 350 bp fragment. 
Primers for the fragment containing human GLO-I gene and $3^{\prime}$ junction of vector, sense (5'-GTA GTG TGG GTG ACT CCT CCG TTC CTT GGG-3') and antisense (5'-TCG AGG GAT CTT CAT AAG AGA AGA G-3'), amplified a 1,200 bp fragment. PCR amplification was carried out with an initial denaturation at $95^{\circ} \mathrm{C}$ for $5 \mathrm{~min}$, followed by 35 cycles of $95^{\circ} \mathrm{C}$ at $30 \mathrm{~s}, 55^{\circ} \mathrm{C}$ or $58^{\circ} \mathrm{C}$ at $30 \mathrm{~s}$ and $72^{\circ} \mathrm{C}$ at 30 or $75 \mathrm{~s}$.

Wild-type rats $(n=9)$ and transgenic $G L O-I$ rats $(n=8)$ were made diabetic by intravenous injection of streptozotocin ( $65 \mathrm{mg} / \mathrm{kg}$ body weight) in the tail vein. Weight- and agematched control rats $(n=9)$ and transgenic GLO-I rats $(n=8)$ were not injected. Streptozotocin resulted in a fivefold increase of blood glucose levels, irrespective of GLO-I overexpression.

Methylglyoxal-modified albumin preparation and characterisation Methylglyoxal was purchased from Sigma Aldrich (St Louis, MO, USA) and methylglyoxalmodified albumin was prepared by incubating human albumin (Cealb; Sanquin, Amsterdam, the Netherlands) in a phosphate buffer $(0.2 \mathrm{~mol} / \mathrm{l}), \mathrm{pH} 7.8$, with 0.5 or $10 \mathrm{mmol} / \mathrm{l}$ methylglyoxal for 2,4 or 8 days. After incubation, the preparations were extensively dialysed against PBS at $4^{\circ} \mathrm{C}$ with three changes of solution. The reagents were divided into aliquots and stored at $20^{\circ} \mathrm{C}$. $N^{E}$-(carboxymethyl)lysine (CML), CEL and MG-H1 were measured by ultra-performance liquid chromatography (tandem) mass spectrometry UPLC-MSMS as previously described [29].

Isometric tension measurements Healthy adult male wildtype Wistar rats or adult Wistar rats with human GLO-I overexpression (GLO-I TG) (300-450 g) were killed by $\mathrm{CO}_{2}$ inhalation. Second-order mesenteric arteries were isolated and then mounted in a myograph organ bath model (610 M; Danish Myotechnology by J. P. Trading, Aarhus, Denmark) with two steel $40 \mu \mathrm{m}$ wires inserted through the lumen of the segments. NO-mediated effects were selectively investigated using acetylcholine $(0.01-10.00 \mu \mathrm{mol} / \mathrm{l})$ and sodium nitroprusside (SNP; $0.01-10.00 \mu \mathrm{mol} / \mathrm{l})$ during contraction with $65 \mathrm{mmol} / 1 \mathrm{~K}^{+}$(which blocks endotheliumderived hyperpolarising factors), following preincubation with the prostaglandin blocker indometacin $(10 \mu \mathrm{mol} / \mathrm{l})$ (details, see Electronic supplementary material [ESM]).

Endothelial cell culture In the in vitro experiments we used ECRF24 cells, which are derived from human umbilical vein endothelial cells, immortalised using an amphotrophic, replication-deficient retrovirus containing the E6/E7 genes of human papilloma virus [30]. Most of the experiments were also performed with HUVEC and showed similar results to those with ECRF24. ECRF24 cells were cultured
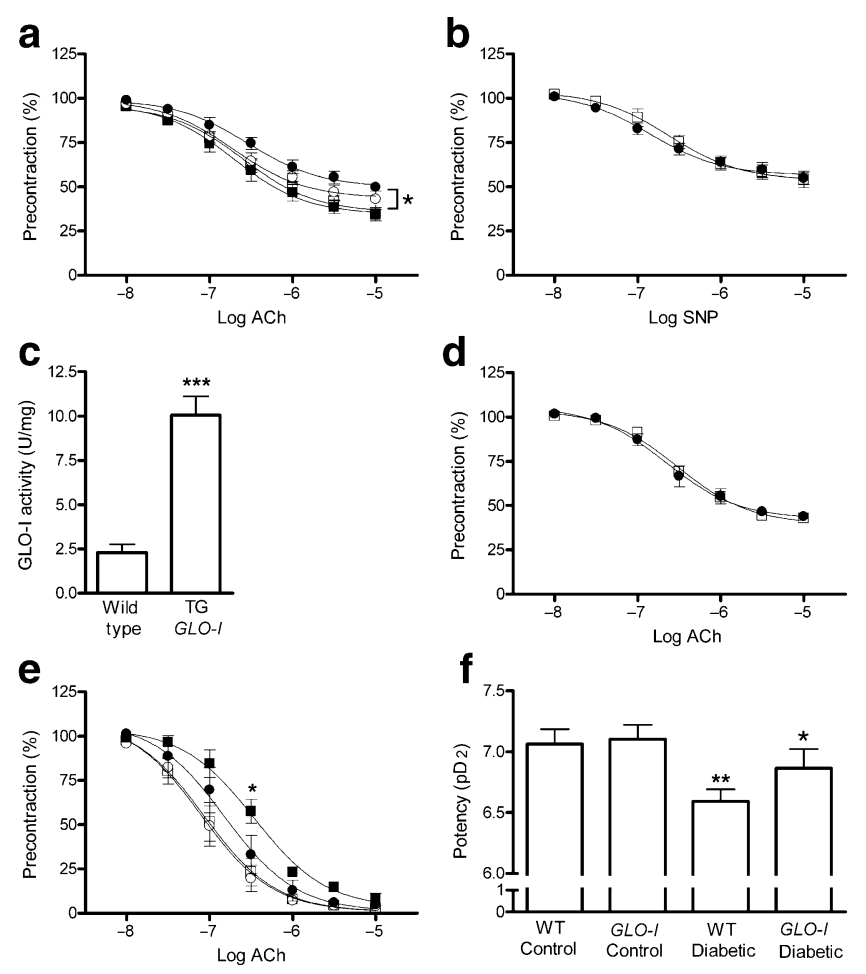

Fig. 1 Effect of high glucose concentration on acetylcholine (ACh)induced NO-mediated endothelium-dependent relaxation in isolated rat mesenteric arteries. a Rat mesenteric arteries were mounted in a myograph and incubated with or without high glucose concentrations for $2 \mathrm{~h}$. Acetylcholine-induced NO-mediated endothelium-dependent relaxation was impaired in a concentration-dependent manner during incubation with $30 \mathrm{mmol} / \mathrm{l}$ glucose (white circles) or $40 \mathrm{mmol} / \mathrm{l}$ glucose (black circles) compared with control $(5 \mathrm{mmol} / \mathrm{l}$ glucose, white squares). The $40 \mathrm{mmol} / \mathrm{l}$ glucose incubation resulted in a statistically significant shift of the dose-response curve ( ${ }^{*} p<0.05$ vs control group). Incubation with $35 \mathrm{mmol} / \mathrm{l}$ mannitol (black squares) as an osmotic control did not impair NO-mediated endothelium-dependent relaxation $(n=6)$. b SNPinduced NO-mediated endothelium-independent vasorelaxation during incubation without (white squares) or with $40 \mathrm{mmol} / \mathrm{l}$ glucose (black circles) for $2 \mathrm{~h}$ did not differ $(n=6)$. c GLO-I activity in mesenteric arteries homogenates of GLO-I transgenic (TG) rats was significantly elevated compared with mesenteric arteries homogenates of wild-type rats $(* * * p<0.001, n=4)$. d In mesenteric arteries of GLO-I transgenic rats, acetylcholine-induced NO-mediated endothelium-dependent relaxation was not impaired during incubation with $40 \mathrm{mmol} / \mathrm{l}$ glucose (black circles) for $2 \mathrm{~h}$ compared with control incubations $(5 \mathrm{mmol} / \mathrm{l}$ glucose, white squares, $n=5)$. e Acetylcholine-induced vasorelaxation was significantly impaired in wild-type diabetic rats (black squares; ${ }^{*} p<0.05$ ) compared with the controls (wild-type control, white squares; transgenic control, white circles). GLO-I overexpression improved this relaxation (black circles; $n=8$ ). $\mathbf{f}$ The decreased potency in wild-type (WT) diabetic rats $(* * p<0.01)$ was significantly improved by $G L O-I$ overexpression $\left({ }^{*} p<0.05\right)$

on fibronectine-coated $75 \mathrm{~cm}^{2}$ flasks and maintained at $37^{\circ} \mathrm{C}$ in $5 \% \mathrm{CO}_{2}$. Culture medium consisted of M199 (with $\mathrm{Na}_{2} \mathrm{HCO}_{3}$ and glutamine; Lonza, Basel, Switzerland) containing $20 \%$ (vol./vol.) heat-inactivated fetal calf serum (HyClone, Logan, UT, USA), $2 \mathrm{mmol} / \mathrm{l}$ glutamine (Invitrogen, San Diego, CA, USA), $100 \mathrm{U} / \mathrm{ml}$ penicillin 
(Invitrogen), $100 \mu \mathrm{g} / \mathrm{ml}$ streptomycin (Invitrogen), $50 \mu \mathrm{g} / \mathrm{ml}$ endothelial cell growth factor (Sigma Aldrich) and $5 \mathrm{U} / \mathrm{ml}$ heparin (Leo Pharma, Breda, the Netherlands).

Immunohistochemistry For immunohistochemistry, arteries were fixed with phosphate-buffered ( $\mathrm{pH}$ 7.4) formaldehyde $\left(4 \%\right.$, vol./vol.) for $30 \mathrm{~min}$ at $37^{\circ} \mathrm{C}$ at the end of the myograph experiments. Subsequently, arteries were transferred to $70 \%$ (vol./vol.) ethanol embedded in paraffin and processed for histological examination. An anti MG-H1 antibody was used to detect the major methylglyoxaladduct MG-H1 and a polyclonal nitrotyrosine antibody (Calbiochem, San Diego, CA, USA) was used for detection of peroxynitrite formation.

Immunofluorescence ECRF24 cells were seeded on chamber slides (Lab-Tek II; Nunc, Rochester, NY, USA), fixed with paraformaldehyde $(4 \%, \mathrm{wt} / \mathrm{vol}$.) and permeabilised with Triton X-100 (0.1\%, vol./vol.). Subsequently mouse antiMG-H1 IgG (1:5000) was used as the primary antibody and FITC-conjugated anti-mouse IgG (1:30; Dako, Glostrup, Denmark) was used as the secondary antibody. Localisation was visualised with a confocal microscope (MRC600; BioRad Laboratories, Hemel Hempstead, UK) equipped with an air-cooled argon-krypton mixed gas laser and mounted on to an Axiophote microscope (Zeiss, Sliedrecht, the Netherlands) using oil-immersion objectives $(\times 40$, numerical aperture $[\mathrm{NA}]=3 \mathrm{D} 1.3$; or $\times 63, \mathrm{NA}=3 \mathrm{D} 1.4)$. Cells incubated without the primary antibodies were used to determine non-specific background fluorescence.

GLO-I assay GLO-I activity was assayed by spectrophotometry according to the method of McLellan and Thornalley, monitoring the increase in absorbance at $240 \mathrm{~nm}$ due to the formation of $S$-D-lactoylglutathione for $10 \mathrm{~min}$ at $25^{\circ} \mathrm{C}$ [31].

Oxidative stress measurement Reactive oxygen species were measured with the 5-(and-6-)-chloromethyl-2'7'dichlorodihydrofluorescein diacetate acetyl ester (CM$\mathrm{H}_{2}$ DCFDA) assay (Invitrogen). In brief, endothelial cells cultured in black 96 wells (Cellstar; Greiner, Monroe, NC, USA) were loaded with $50 \mu \mathrm{mol} / 1 \mathrm{CM}-\mathrm{H}_{2} \mathrm{DCFDA}$ for $45 \mathrm{~min}$. Subsequently, cells were incubated with $1.0 \mathrm{mmol} / 1$ methylglyoxal (with or without $100 \mu \mathrm{mol} / 1 \mathrm{~N}$-acetyl-Lcysteine [NAC], $10 \mathrm{nmol} / 1$ EUK-134 and $10 \mathrm{nmol} / 1$ $\mathrm{Mn}[\mathrm{III}] \mathrm{TMP}$ pre-treatment), with simultaneous fluorescent signal $(485 / 516 \mathrm{~nm})$ measurement by micro-plate reader (Synergy Biotek, Winooski, VT, USA) during $60 \mathrm{~min}$. Results are shown as arbitrary units (normalised fluorescent signal produced during $60 \mathrm{~min}) \pm \mathrm{SEM}$.

Cell viability assay To assess cell viability, a 3-(4,5dimethylthiazol-2-yl)-2,5-diphenyl tetrazolium bromide
(MTT; Invitrogen) assay was used. Briefly, endothelial cells were seeded at a density of $1 \times 10^{4}$ cells per well into 96-well culture plates. Confluent monolayers were then exposed to various methylglyoxal concentrations $(0.1,0.33$ and $1.0 \mathrm{mmol} / \mathrm{l}$ ) for $60 \mathrm{~min}$. Afterwards cells were incubated with MTT for $3 \mathrm{~h}$ and lysed with hydrogen chloride/isopropanol. Subsequently absorbance was measured at $570 \mathrm{~nm}$ and at $690 \mathrm{~nm}$ for background subtraction.

NO measurement Deoxygenated water was spiked with -NO gas and the $\bullet \mathrm{NO}$ concentration was monitored with an Iso-NO meter (World Precision Instruments, Sarasota, FL, USA) at $37^{\circ} \mathrm{C}$ and the decrease in $\cdot \mathrm{NO}$ concentration followed in time in the presence or absence of the test compound in solution (for details, see ESM).

Statistical analysis All values are expressed as mean \pm SEM. Sensitivity $\left(\mathrm{pD}_{2}\right)$ and maximum response $\left(E_{\max }\right)$ were calculated from the concentration-response curves to acetylcholine. $\mathrm{pD}_{2}$ was defined as the negative logarithm to base 10 of the $\mathrm{EC}_{50}$ values and $E_{\max }$ was defined as the maximal vasorelaxation to acetylcholine at the highest concentration used and expressed as 100 minus percentage relative contractions to $65 \mathrm{mmol} / 1 \mathrm{~K}^{+}$. The statistical differences in potency and maximum response between groups was tested using one-way ANOVA and the shift of the dose-response curve was tested with two-way ANOVA with a post hoc Bonferroni correction. A $p$ value of less than 0.05 was considered statistically significant.

\section{Results}

Hyperglycaemia-induced impairment of NO-mediated relaxation in rat mesenteric arteries is normalised by GLO-I overexpression To investigate the effects of high glucose on vascular reactivity, isolated mesenteric arteries were mounted in a myograph and exposed to 30 and $40 \mathrm{mmol} / \mathrm{l}$ glucose for $2 \mathrm{~h}$. Endothelium-dependent NO-mediated relaxation was tested in these arteries during precontraction with high potassium $(65 \mathrm{mmol} / \mathrm{l})$ in the presence of $10 \mu \mathrm{mol} / \mathrm{l}$ indometacin. High glucose did not lead to any alterations in precontraction (active wall tension in response to $65 \mathrm{mmol} / \mathrm{l}$ potassium was $2.8 \pm 0.6 \mathrm{~N} / \mathrm{m}$ ). Pre-incubation with 30 or $40 \mathrm{mmol} / 1$ glucose reduced acetylcholine-induced vasorelaxation (Fig. 1a). The efficacy significantly decreased ( $E_{\max }$ in presence of 5,30 and $40 \mathrm{mmol} / 1$ glucose was $67 \pm 2$, $56 \pm 3$ and $50 \pm 3 \%$ vasorelaxation, respectively; $p<0.01$ ), but the potency of acetylcholine was not altered $\mathrm{pD}_{2}$ in presence of 5,30 and $40 \mathrm{mmol} / 1$ glucose $6.6 \pm 0.1,6.7 \pm 0.1$ and $6.5 \pm 0.1$, respectively). This effect of glucose was not due to changes in osmotic values as indicated by normal relaxing responses to the osmotic control mannitol ( $E_{\max } 65 \pm 3 \%$, 
$\left.\mathrm{pD}_{2} \quad 6.7 \pm 0.1\right)$. The effect of high glucose was strictly endothelium-dependent, because no alterations in endothelium-independent relaxation were provoked with the NO-donor SNP (Fig. 1b).

To study whether intracellular accumulation of methylglyoxal is involved in high glucose-induced impairment of acetylcholine-induced vasorelaxation, mesenteric arteries of rats with transgenic overexpression of the cytosolic GLO-I enzyme were used. In these transgenic rats we measured a significant increase $(p<0.001)$ in GLO-I activity in the mesenteric arteries compared with their wild-type littermates (Fig. 1c). GLO-I overexpression prevented high glucose-induced impairment of endothelium-dependent NO-mediated relaxation (Fig. 1d), indicating that methylglyoxal is involved in high glucose-induced impairment of vasorelaxation. To test whether methylglyoxal is also involved in hyperglycaemia-induced impairment of vascular reactivity in vivo, we tested acetylcholine-induced vasorelaxation in the mesenteric arteries of wild-type and transgenic GLO-I rats with or without diabetes. Wild-type diabetic rats had decreased vascular reactivity to acetylcholine (and not to SNP; data not shown), which was improved by GLO-I overexpression (Fig. 1e). The potency of acetylcholine in the mesenteric arteries was markedly decreased in wild-type diabetic rats and significantly improved by GLO-I overexpression in transgenic rats (Fig. 1f).

Extracellularly added methylglyoxal-derived AGEs do not lead to impaired vasoreactivity To test a possible extracellular contribution of methylglyoxal-derived AGEs to vascular reactivity, methylglyoxal-modified albumin was added to the mesenteric arteries. Minimally and highly modified methylglyoxal-albumin was prepared by incubating albumin with 0.5 and $10 \mathrm{mmol} / 1$ methylglyoxal respectively for 2, 4 or 8 days. Concentrations of the AGEs CML, CEL and MG-H1 in the albumin preparations incubated for 2 days are shown in Fig. $2 \mathrm{a}-\mathrm{c}$. None of these methylglyoxal-albumin preparations modified contractile responses or acetylcholine-induced vasorelaxation in rat mesenteric resistance arteries, demonstrating that vasoreactivity is not functionally impaired by extracellular methylglyoxal-modified albumin adducts (Fig. 2d). Also albumin modified with methylglyoxal for 4 or 8 days did not affect reactivity compared with control albumin (data not shown). In contrast, under the same experimental conditions, the RAGE ligand S100b significantly $(p<0.01)$ reduced acetylcholine-induced NO-mediated vasorelaxation in a dose-dependent manner (Fig. 2e).

Methylglyoxal leads to impaired endothelium-dependent vasorelaxation To determine the direct effect of methylglyoxal on vasoreactivity, rat mesenteric resistance arteries
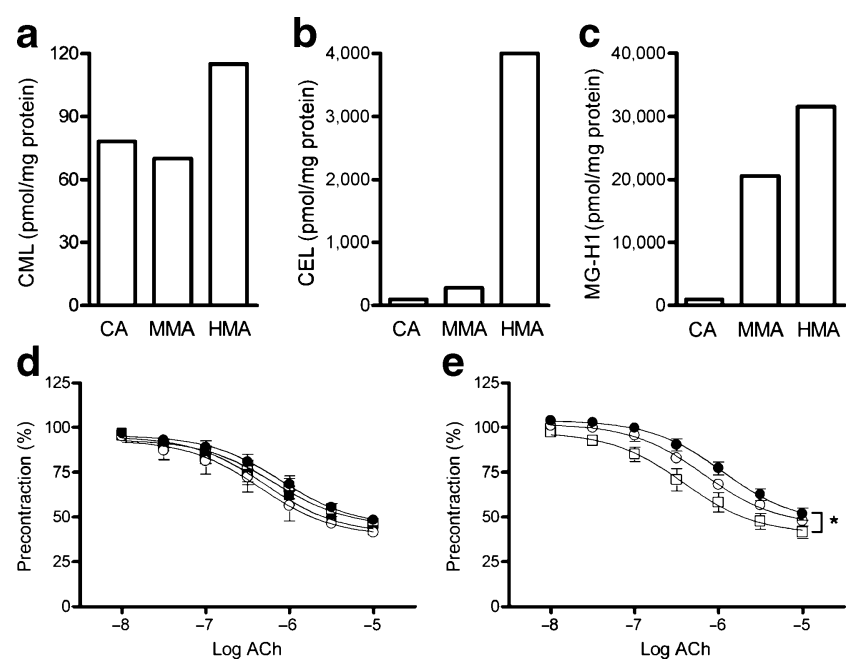

Fig. 2 Effect of methylglyoxal-modified albumin and S100b on acetylcholine-induced NO-mediated endothelium-dependent relaxation in isolated rat mesenteric arteries. a-c Characteristics of methylglyoxalmodified albumin (MMA). Control albumin (CA) was exposed to methylglyoxal $(0.5$ and $10 \mathrm{mmol} / \mathrm{l})$ for 2 days to prepare minimally modified methylglyoxal-albumin and highly modified methylglyoxalalbumin (HMA). The amount of CML (a), CEL (b) and MG-H1 (c) was determined by UPLC-MSMS analysis. d Acetylcholine (ACh)-induced NO-mediated endothelium-dependent relaxation during incubation with albumin (black squares), minimally modified methylglyoxal-albumin (white circles) and highly modified methylglyoxal-albumin (black circles) did not statistically differ from the control group (white squares); $n=4$. e Incubation of mesenteric arteries with 20 (white circles) or $40 \mu \mathrm{g} / \mathrm{ml}$ (black circles) of the RAGE ligand S100b resulted in concentration-dependent impairment of acetylcholine-induced NO-mediated endothelium-dependent relaxation. The $40 \mu \mathrm{g} / \mathrm{ml}$ incubation resulted in a statistically significant shift of the dose-response curve; ${ }^{*} p<0.05$ vs control group, $n=4$

were exposed to methylglyoxal. The average isometric tension generated by the vessels during precontraction with high potassium $(65 \mathrm{mmol} / \mathrm{l})$ was $3.1 \pm 0.5 \mathrm{~N} / \mathrm{m}$ and did not significantly differ between the various incubations. Preincubation of the arteries with methylglyoxal significantly reduced acetylcholine-induced vasorelaxation in the presence of $10 \mu \mathrm{mol} / 1$ indometacin in a concentration-dependent manner (Fig. 3a), as indicated by a significantly decreased efficacy $\left(E_{\max }\right.$ in presence of $0,0.1,0.33$ and $1.0 \mathrm{mmol} / \mathrm{l}$ methylglyoxal $62 \pm 3,57 \pm 1,48 \pm 3$ and $39 \pm 3 \%$, respectively; $p<0.001)$. In contrast, the potency of acetylcholine was not altered $\left(\mathrm{pD}_{2}\right.$ in presence of $0,0.1,0.33$ and $1.0 \mathrm{mmol} / 1$ methylglyoxal $6.5 \pm 0.1,6.3 \pm 0.1,6.2 \pm 0.1$ and $6.3 \pm 0.2$, respectively). Longer incubations with lower amounts of methylglyoxal (10 and $50 \mu \mathrm{mol} / \mathrm{l}$ for $2 \mathrm{~h}$ ) also impaired NO-mediated vasorelaxation as indicated by decreased efficacy $\left(E_{\max }\right.$ in presence of 0,10 and $50 \mu \mathrm{mol} / 1$ methylglyoxal $58 \pm 2,55 \pm 2$ and $46 \pm 3 \%$, respectively; $p<0.01$; Fig. $3 b$ ). The impairment of acetylcholine-induced vasorelaxation by methylglyoxal was endothelium-dependent, as indicated by normal relaxing responses of arteries pre-incubated with methylglyoxal to the endothelium-independent NO donor SNP (Fig. 3c). 

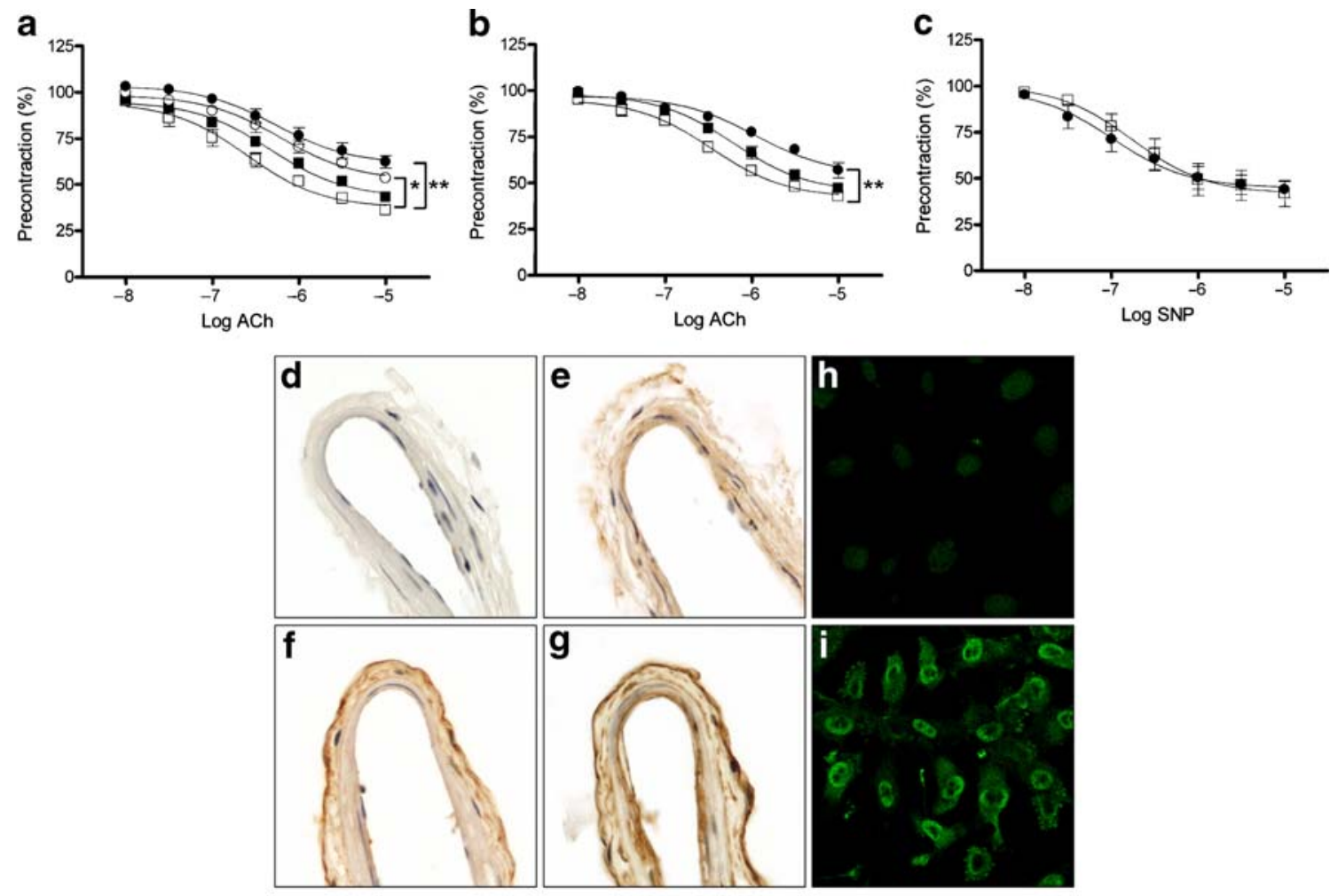

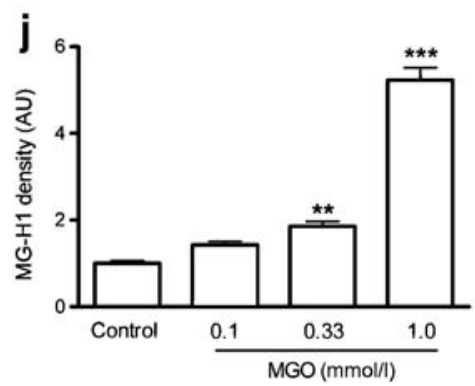

Fig. 3 Effect of methylglyoxal on vascular reactivity and intracellular MG-H1 formation. a Incubation of isolated mesenteric arteries for $1 \mathrm{~h}$ with $0.1 \mathrm{mmol} / 1$ (black squares), $0.33 \mathrm{mmol} / 1$ (white circles) and $1.0 \mathrm{mmol} / \mathrm{l}$ (black circles) methylglyoxal resulted in impairment of acetylcholine (ACh)-induced NO-mediated endothelium-dependent relaxation compared with the control group (white squares); $n=5$ for all conditions. Incubation with $0.33 \mathrm{mmol} / 1$ and $1.0 \mathrm{mmol} / 1$ methylglyoxal resulted in a statistically significant shift of the dose-response curve $\left({ }^{*} p<0.05\right.$ and $* * * p<0.001$ respectively vs control group; $\left.n=5\right)$. b Incubation of isolated mesenteric arteries for $2 \mathrm{~h}$ with $10 \mu \mathrm{mol} / \mathrm{l}$ (black squares) and $50 \mu \mathrm{mol} / \mathrm{l}$ (black circles) methylglyoxal resulted in impairment of acetylcholine-induced NO-mediated endotheliumdependent relaxation compared with the control group (white squares); $n=4$ for all conditions. Incubation with $50 \mu \mathrm{mol} / \mathrm{l}$ methylglyoxal resulted in a statistically significant shift of the dose-response curve $\left({ }^{* *} p<0.01\right.$ vs

Exposure of the mesenteric arteries to methylglyoxal leads to accumulation of the major methylglyoxal-derived AGE, MG$\mathrm{H} 1$, which was predominantly localised in the adventitia and the endothelium (Fig. $3 \mathrm{~d}-\mathrm{g}$ ). To confirm the accumulation of MG-H1 by methylglyoxal treatment and to further address

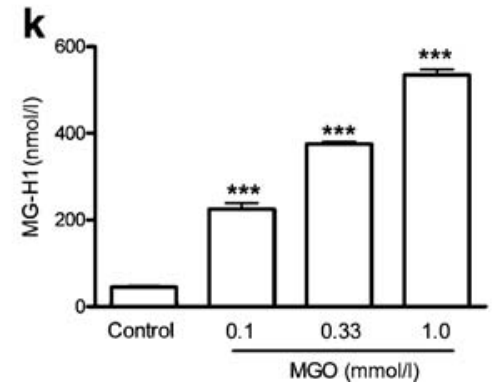

control group; $n=4)$. c SNP-induced NO-mediated endotheliumindependent vasorelaxation during incubation without (white squares) or with $1.0 \mathrm{mmol} / \mathrm{l}$ methylglyoxal (black circles) for $1 \mathrm{~h}$ did not differ $(n=4)$. d-i Localisation of MG-H1 in adventitia and endothelial cells of mesenteric arteries not incubated (d) or incubated with $0.1 \mathrm{mmol} / \mathrm{l}(\mathbf{e})$, $0.33 \mathrm{mmol} / \mathrm{l}$ (f) or $1.0 \mathrm{mmol} / \mathrm{l}(\mathrm{g})$ methylglyoxal for $1 \mathrm{~h}$. Intracellular localisation of MG-H1 was also determined by confocal laser scanning microscopy in cultured endothelial cells (ECRF24) incubated without (h) or with $1.0 \mathrm{mmol} / \mathrm{l}$ methylglyoxal (i) for $1 \mathrm{~h}$. $\mathbf{j}$ Quantification of MGH1 staining in arteries exposed to methylglyoxal $(n=4)$. $\mathbf{k}$ Concentration-dependent increase of MG-H1 levels in protein lysates of mesenteric arteries not incubated (Control) or incubated with $0.1,0.33$ or $1.0 \mathrm{mmol} / 1$ methylglyoxal (MGO) for $1 \mathrm{~h}$ as determined by UPLC-MSMS $(n=3)$. j, $\mathbf{k}^{* *} p<0.01$ and ${ }^{* * *} p<0.001$ vs control group. AU, arbitrary units

the localisation of MG-H1 in endothelial cells, we incubated endothelial cells with methylglyoxal and showed intracellular localisation of MG-H1 predominantly in the cytoplasm and the nucleus of these endothelial cells (Fig. 3i). MG-H1 accumulation of methylglyoxal in mesenteric arteries was 
concentration-dependent as indicated by quantification of immunostaining of MG-H1 (Fig. 3j) and by UPLC-MSMS (Fig. 3k). These experiments demonstrated that extracellularly added methylglyoxal results in intracellular accumulation of MG-H1.

Intracellular effects of methylglyoxal contribute to methylglyoxal-induced impairment of endotheliumdependent vasorelaxation To study whether the intracellular accumulation of methylglyoxal and/or MG-H1 is involved in methylglyoxal-induced impairment of acetylcholine-induced vasorelaxation, arteries of GLO-I transgenic rats were incubated with $1.0 \mathrm{mmol} / \mathrm{l}$ methylglyoxal. These arteries did not show elevated MG-H1 levels, while methylglyoxalincubated arteries of wild-type rats did (Fig. 4a-d). Furthermore, the impaired vasoreactivity of methylglyoxal-incubated mesenteric arteries of rats was normalised by GLO-I overexpression (Fig. 4e), indicating that extracellularly added methylglyoxal leads to intracellular processes that contribute to methylglyoxal-impaired endothelium-dependent vasorelaxation.

Methylglyoxal incubation leads to increased peroxynitrite via formation of reactive oxygen species To investigate a possible role of ROS in the impairment of acetylcholineinduced vasorelaxation by methylglyoxal, we stained rat mesenteric arteries for nitrotyrosine after exposure to the endothelial nitric oxide synthase (eNOS) stimulus acetylcholine (Fig. 5a-d). Nitrosylation of tyrosine residues is a well-known marker for peroxynitrite formation, an oxidant product of NO. In parallel to MG-H1 accumulation, we observed that methylglyoxal resulted in an increase in nitrotyrosine staining in the same dose-dependent manner (Fig. 5e). This staining was not limited to specific regions of the vessel wall. Methylglyoxal-induced peroxynitrite formation was inhibited by treatment of the arteries with the NOS blocker L-NAME (data not shown).

To confirm that methylglyoxal contributes to ROS production in the endothelium, we used a fluorescent probe in endothelial cells to monitor ROS production. In CM$\mathrm{H}_{2}$ DCFDA-loaded endothelial cells, methylglyoxal treatment resulted in a concentration-dependent increase in oxidative stress formation (Fig. 5f). Direct incubation of the DCF probe with methylglyoxal did not lead to any increase in fluorescent signal, thereby excluding a non-specific methylglyoxal effect (data not shown). To exclude possible cytotoxic effects of methylglyoxal on the endothelial cells, we performed a cell viability assay. The MTT assay showed no significant levels of cytotoxicity after $1 \mathrm{~h}$ treatment with $0.1,0.33$ and $1.0 \mathrm{mmol} / 1$ methylglyoxal $(100 \pm 4 \%, 98 \pm 3 \%$ and $97 \pm 5 \%$ viability compared with control cells, respectively). In addition, eNOS staining of the mesenteric arteries also showed that the endothelial cell layer remained intact
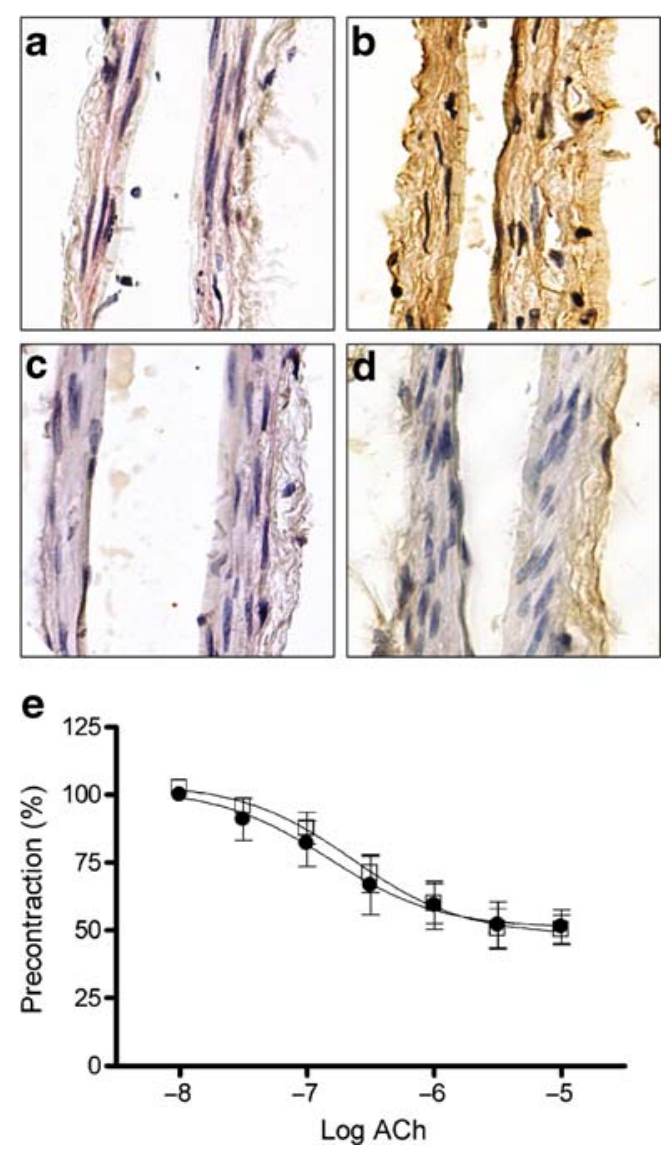

Fig. 4 Effect of GLO-I overexpression on methylglyoxal (MGO)induced formation of the major methylglyoxal-adduct MG-H1 and on vascular reactivity. a-d Compared with MG-H1 staining in mesenteric arteries of wild-type rats incubated without (a) and with $1.0 \mathrm{mmol} / 1$ methylglyoxal (b), incubation for $1 \mathrm{~h}$ with $1.0 \mathrm{mmol} / \mathrm{l}$ methylglyoxal did not lead to intracellular MG-H1 formation in GLO-I transgenic rats incubated without (c) and with $1.0 \mathrm{mmol} / 1$ methylglyoxal (d). e In mesenteric arteries of GLO-I transgenic rats, acetylcholine (ACh)induced NO-mediated endothelium-dependent relaxation was not impaired during incubation with $1.0 \mathrm{mmol} / \mathrm{l}$ methylglyoxal (black circles) for $1 \mathrm{~h}$ compared with control incubation (white squares) $(n=4)$

after exposure to $1.0 \mathrm{mmol} / \mathrm{l}$ methylglyoxal. There were no signs of apoptosis as indicated by absence in the staining of the apoptotic marker cleaved caspase-3 (data not shown).

We also investigated whether free methylglyoxal or methylglyoxal-derived AGEs have a direct effect on NO. Free methylglyoxal, but not highly modified methylglyoxalalbumin, did lead to increased breakdown of NO (Fig. $5 \mathrm{~g}$ ). Under the conditions used, the reaction between methylglyoxal and NO could be fitted according to a (pseudo) firstorder reaction $\left(\log k=1.05 \pm 0.13 \mathrm{~mol} \mathrm{l}^{-1} \mathrm{~s}^{-1}\right)$. The results show that methylglyoxal reduced the half-life of NO in buffer from $4.3 \pm 0.1 \mathrm{~min}$ to approximately $0.8 \pm 0.2 \mathrm{~min}$. In comparison, under the same experimental conditions, the rate 

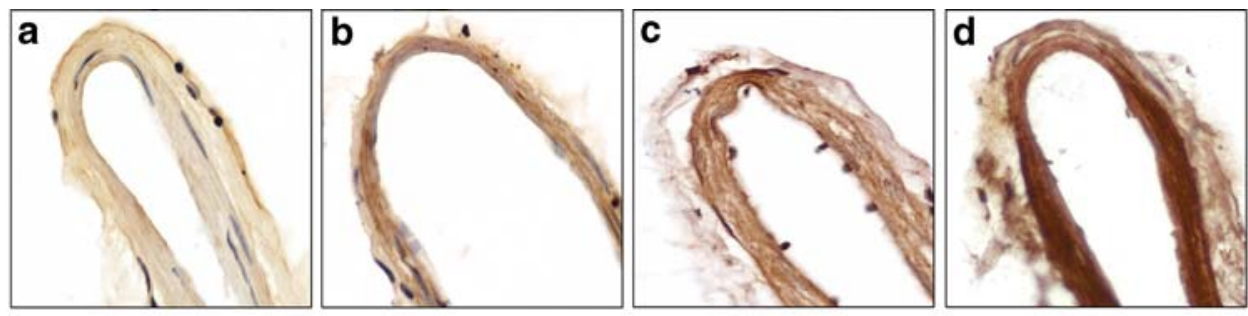
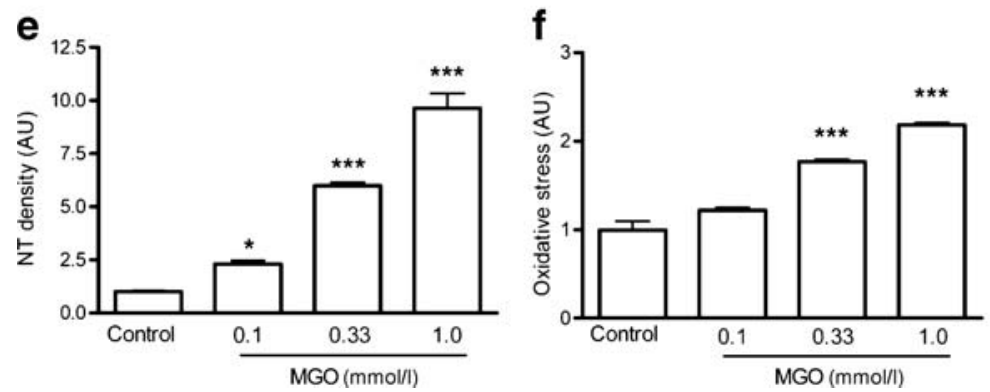

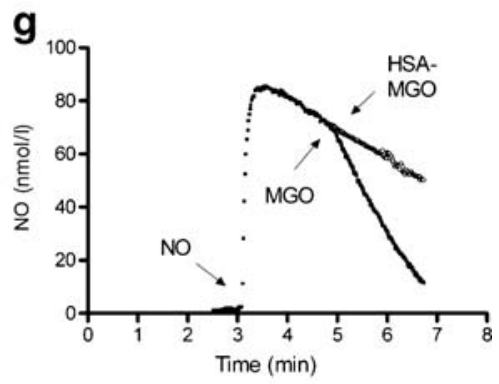

Fig. 5 Methylglyoxal (MGO)-induced oxidative stress formation in isolated mesenteric arteries and cultured endothelial cells, and direct quenching of NO. a-d Representive staining of nitrotyrosine (NT) in mesenteric resistance arteries not incubated (a) or incubated for $1 \mathrm{~h}$ with $0.1 \mathrm{mmol} / 1$ (b), $0.33 \mathrm{mmol} / 1$ (c) or $1.0 \mathrm{mmol} / 1$ (d) methylglyoxal. e Quantification of NT staining in methylglyoxal-incubated arteries $(n=4)$. f Oxidative stress formation in endothelial cells as measured with a $\mathrm{CM}-\mathrm{H}_{2}$ DCFDA probe during treatment for $1 \mathrm{~h}$ with methylglyoxal as shown; $n=3$. g Direct effect of methylglyoxal (MGO) and methylglyoxal-modified human albumin (HSA-MGO) on $\mathrm{NO}$ as measured with an Iso-NO meter in deoxygenated buffer. ${ }^{*} p<0.05$ and $* * * p<0.001$ vs control group. AU, arbitrary units constant found for the potent NO-quenching molecule haemoglobin was $1.0 \times 10^{4} \mathrm{~mol} \mathrm{l}^{-1} \mathrm{~s}^{-1}[32]$.

Antioxidant treatment prevents impaired vasorelaxation by methylglyoxal The results so far suggest a reduction of NO bioavailability by methylglyoxal via induction of ROS formation. In line with this, pre-incubation of the mesenteric arteries with the antioxidants EUK-134, Mn(III)TMP and NAC prevented methylglyoxal impairment of acetylcholineinduced vasorelaxation (Fig. 6a). In addition, preincubation with the $\mathrm{NAD}(\mathrm{P}) \mathrm{H}$ oxidase inhibitor apocynin prevented decreased vascular relaxation (ESM Fig. 1).Vessels incubated with antioxidants showed less nitrotyrosine staining upon incubation with $1.0 \mathrm{mmol} / \mathrm{l}$ methylglyoxal (Fig. 6b-f, g), but MG-H1 levels were not altered (Fig. 6h). In accordance, in cultured endothelial cells, the antioxidants also led to reduction of methylglyoxal-induced oxidative stress as measured with the CM- $\mathrm{H}_{2}$ DCFDA probe (Fig. 6i).

\section{Discussion}

In this study we have shown that hyperglycaemia-induced impairment of endothelium-dependent NO-mediated vasorelaxation of mesenteric arteries is mediated by the major AGE precursor methylglyoxal. The effect of methylglyoxal occurs intracellularly and is most likely to be caused by decreased bioavailability of NO due to a methylglyoxalinduced increase of oxidative stress. These data provide a mechanistic link between hyperglycaemia, the formation of the AGE precursor methylglyoxal and vascular complications.

Endothelial dysfunction is characterised by impaired vascular response to endothelium-derived $\mathrm{NO}$ and is associated with the development of micro- and macrovascular complications in diabetes [33]. To gain insight into the mechanism by which hyperglycaemia alters endothelial function, we used acetylcholine, which stimulates the release of NO from endothelial cells, leading to relaxation of the underlying smooth muscle cells. Experiments were performed in the presence of indometacin and elevated $\mathrm{K}^{+}$ concentration to rule out involvement of endotheliumderived prostaglandins and hyperpolarising factors, and thus to focus on NO-mediated relaxation. Treatment of arteries with high concentrations of glucose significantly decreased acetylcholine-induced NO-mediated vasorelaxation (Fig. 1), which is in agreement with a previous study performed in mesenteric arteries [34]. We also found that the effect of high glucose was prevented in arteries with GLO-I overexpression and that the impaired relaxation in diabetic rats was improved by GLO-I overexpression. In addition, incubation with exogenous methylglyoxal resulted in dose-dependent impairment of acetylcholine-induced vasorelaxation (Fig. 3). These data from ex vivo and in vivo experiments provide strong evidence that the impair- 


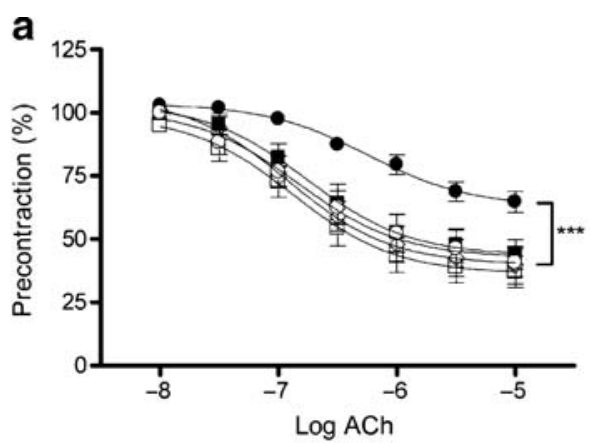

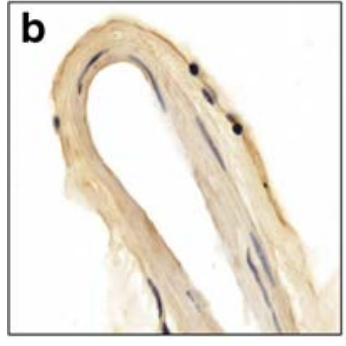

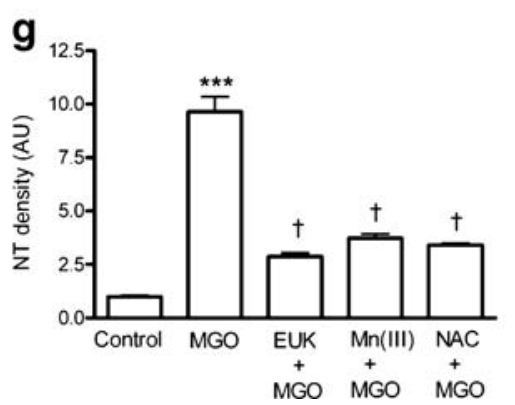

Fig. 6 Effect of antioxidants on the effect of methylglyoxal on vascular reactivity and oxidative stress formation. a Acetylcholine (ACh)-induced NO-mediated endothelium-dependent relaxation during incubation without (white squares) or with $1.0 \mathrm{mmol} / \mathrm{l}$ methylglyoxal (black circles) for $1 \mathrm{~h}$ with or without pre-incubation for 20 min with the antioxidants NAC (1.0 mmol/l) (white diamonds), EUK-134 (1 $\mu \mathrm{mol} / 1)$ (black squares) or Mn(III)TMP $(1 \mu \mathrm{mol} / 1)$ (white circles). Treatment of mesenteric arteries with $1.0 \mathrm{mmol} / \mathrm{l}$ methylglyoxal in the absence of antioxidant resulted in a significant shift in the dose-response curve compared with the control group $(* * * p<0.001)$. All antioxidant pretreatments prevented methylglyoxalinduced impairment of reactivity $(n=5)$. b-f Nitrotyrosine staining of arteries incubated without (b), or with $1.0 \mathrm{mmol} / \mathrm{l}$ methylglyoxal (c) and

ment of endothelium-dependent NO-mediated vasorelaxation in diabetes is mediated by the major AGE precursor methylglyoxal.

Since the arterial contractile responses to $\mathrm{K}^{+}$and relaxing responses to the NO-donor SNP were not modified by methylglyoxal, our data indicate that short exposure to methylglyoxal leads to an endothelium-dependent effect on vasorelaxation without a direct effect of methylglyoxal on arterial smooth muscle function. In accordance, Mukohda et al. showed that methylglyoxal had no effects on $\mathrm{K}^{+}$-induced contraction [35]. Although not tested in our study, chronic exposure to exogenous methylglyoxal may also lead to impaired endothelium-independent vasorelaxation [36].

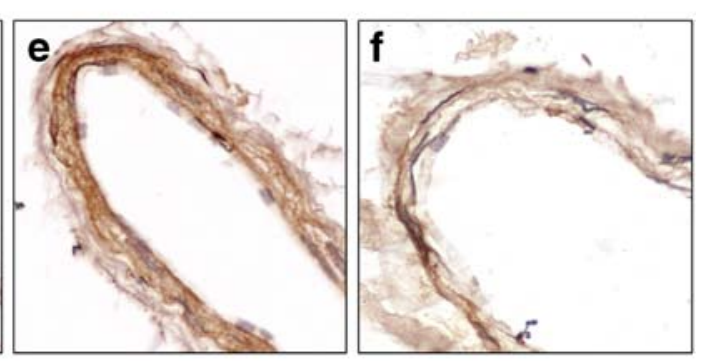

i

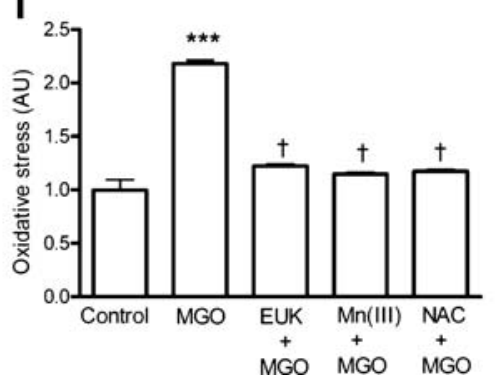

after pre-incubation with $1.0 \mathrm{mmol} / \mathrm{l} \mathrm{NAC} \mathrm{(d),} 1 \mu \mathrm{mol} / \mathrm{l}$ EUK-134 (e) or $1 \mu \mathrm{mol} / 1 \mathrm{Mn}(\mathrm{III}) \mathrm{TMP}$ (f). $\mathbf{g}$ Quantification of NT staining in mesenteric arteries after treatment with $1.0 \mathrm{mmol} / \mathrm{l}$ methylglyoxal (MGO) without or with pre-incubation NAC, EUK-134 or Mn(III)TMP $(n=4)$. h Quantification of MG-H1 staining in mesenteric arteries after treatment with $1.0 \mathrm{mmol} / \mathrm{l}$ methylglyoxal without or with pre-incubation at the same concentrations of NAC, EUK-134 or Mn(III)TMP. i Oxidative stress formation measured with a CM- $\mathrm{H}_{2}$ DCFDA probe in ECRF24 cells after treatment with $1.0 \mathrm{mmol} / \mathrm{l}$ methylglyoxal without or with pre-incubation at $100 \mu \mathrm{mol} / 1 \mathrm{NAC}, 10 \mathrm{nmol} / 1$ EUK-134 and $10 \mathrm{nmol} / 1 \mathrm{Mn}(\mathrm{III}) \mathrm{TMP}(n=3)$. g-i $* * * p<0.001$ vs control group; $\uparrow p<0.001$ vs methylglyoxal group. AU, arbitrary units

We did not find any effects of extracellularly added methylglyoxal-modified albumin on vascular reactivity (Fig. 2). In accordance with this result, we had previously demonstrated that there is also no binding and biological effect of methylglyoxal-modified albumin on endothelial cells [37]. In contrast, $\mathrm{Xu}$ et al. [11] showed that other extracellularly formed AGEs can impair endotheliumdependent vasorelaxation, but these data were obtained with AGE-albumin, which was prepared with a degree of modification that is much higher than that ever seen in diabetes. A recent paper by Gao et al. [38] described the importance of S100b-induced RAGE activation in endothelial dysfunction and impaired vasoreactivity. We con- 
firmed the finding that the RAGE ligand $\mathrm{S} 100 \mathrm{~b}$ reduces acetylcholine-induced NO-mediated vasorelaxation (Fig. 2e). Combined, these data provide strong evidence that extracellular methylglyoxal-derived AGEs are not involved in diabetic arterial dysfunction and that other ligands for RAGE, such as CML and S100b, impair endothelium-dependent vasorelaxation.

Another important finding of our study is that the effect of hyperglycaemia and methylglyoxal on NO-mediated vasorelaxation in rat mesenteric arteries is completely abolished in rat mesenteric arteries with overexpression of GLO-I, indicating that the effect of hyperglycaemia and exogenous methylglyoxal is due to intracellular effects of methylglyoxal in endothelial cells. We recently found that endothelial cells incubated with high glucose concentrations display an increase in methylglyoxal [18] and we have now demonstrated that methylglyoxal leads to intracellular accumulation of the major methylglyoxal-induced AGE, MG-H1. This is in agreement with a study showing that methylglyoxal, given intraperitoneally to rats for 7 weeks, induces an increase in vascular AGE content [36]. In our study, MG-H1 appeared to be localised in the cytoplasm and in the nucleus of endothelial cells. The latter is in accordance with data of two recent papers about methylglyoxal modification of nuclear proteins [39, 40]. Furthermore, Schlotterer et al. [41] recently reported that hyperglycaemia leads to methylglyoxal-modified mitochondrial proteins and reduced lifespan in C. elegans. This oxidative stress-dependent process was inhibited by GLO-I overexpression, thereby linking methylglyoxal to the formation of ROS.

Chronic hyperglycaemia is associated with increased intracellular levels of methylglyoxal [18, 42], oxidative stress [43, 44] and an impairment of NO synthesis pathways [45]. Our results link these studies by showing an oxidative stress-dependent effect of methylglyoxal on NO bioavailability. This impairment was prevented by superoxide dismutase mimetics and by the antioxidant NAC (Fig. 6). Moreover, the impaired relaxation could also be prevented by apocynin, but because of the lack of specificity of this $\mathrm{NAD}(\mathrm{P}) \mathrm{H}$ inhibitor [46], the exact mechanism by which methylglyoxal induces the formation of ROS is not completely clear. Although not addressed in this study, methylglyoxal modifications of mitochondrial membrane proteins [27], antioxidant enzymes [47] and GAPDH [48] may increase oxidative stress and, as a consequence, impair endothelium-dependent vasorelaxation.

Because AGEs are known to inactivate NO by a direct chemical reaction, the impaired endothelium-dependent vasodilatation in diabetes may be mediated by NO quenching and NO depletion by methylglyoxal-derived AGE accumulation [49]. Indeed, we observed quenching of NO by methylglyoxal, but not by methylglyoxal-derived
AGEs. Methylglyoxal reduced the half-life of NO in buffer from 4 to approximately $1 \mathrm{~min}$. However, in vivo the very fast reaction of NO with numerous bio-molecules, such as haemoglobin, is one of the reasons why the half-life of NO in biological systems is very short, i.e. less than $1 \mathrm{~s}$ [50], and not susceptible to being shortened by methylglyoxal. Therefore, the physiological relevance of quenching of NO by methylglyoxal, for example in methylglyoxal-induced impairment of endothelium-dependent vasodilatation, is very limited. Methylglyoxal and methylglyoxal-derived AGEs may also decrease NO availability by decreasing NO synthase activity, but in our previous study we already ruled out the possibility that free methylglyoxal and the methylglyoxal-derived AGEs argpyrimidine and MG-H1, which have some structural homology with the NOS inhibitor asymmetric dimethylarginine, directly inhibit eNOS activity [51]. Together, these findings indicate that the effects of methylglyoxal on vasoreactivity are thus caused by methylglyoxal-induced oxidative stress and the quenching of NO by oxidative stress, rather than direct interaction of methylglyoxal-adducts with $\mathrm{NO}$ or eNOS activity. The question of whether methylglyoxal or methylglyoxal-induced AGEs are involved in impaired eNOS activation by oxidative-stress-related interference with eNOS phosphorylation needs to be further investigated.

For the ex vivo and in vitro experiments, we used methylglyoxal in a range of 10 to $1,000 \mu \mathrm{mol} / 1$, a range that caused effects in a concentration-dependent manner. The in vivo concentration of methylglyoxal is under debate; plasma methylglyoxal levels are estimated to be about $0.5 \mu \mathrm{mol} / 1$ in healthy individuals and can increase twofold in diabetes [52], while others have demonstrated that plasma methylglyoxal concentration in poorly controlled human diabetic patients is about $400 \mu \mathrm{mol} / 1$ [53]. Nevertheless, cells produce large amounts of methylglyoxal [54] and therefore intracellular levels are probably much higher than plasma levels [55]. Although the maximum concentration of methylglyoxal used in the present study appears to be higher than levels observed in vivo, this concentration was also used to increase intracellular concentrations and to mimic life time exposure to elevated levels of methylglyoxal such as in diabetes and in hypertension. Under our experimental conditions, exposure to elevated methylglyoxal levels did not lead to cytotoxic effects.

What are the clinical implications of these observations? Because higher plasma levels of methylglyoxal have been demonstrated under postprandial conditions [36] and in plasma of diabetic patients [17], as well as in endothelial cells incubated with high glucose concentrations [18, 43], we propose here that methylglyoxal plays a crucial role in impaired endothelium-dependent vasorelaxation under postprandial conditions and in chronic hyperglycaemia, and in the long term in development of vascular complications. 
In summary, we found that hyperglycaemia-induced impairment of endothelium-dependent NO-mediated vasorelaxation is prevented by $G L O-I$ overexpression and that methylglyoxal decreased NO-mediated vasorelaxation due to an increase in oxidative stress. We conclude that hyperglycaemia-induced impairment of endothelium-dependent vasorelaxation is mediated by intracellular methylglyoxal levels in an oxidative stress-dependent pathway. These data provide a new mechanistic link between hyperglycaemia, the formation of methylglyoxal-derived AGEs and vascular complications.

Acknowledgements This study was partially supported by the Dutch Diabetes Foundation (grant number 2005.11.013).

Duality of interest The authors declare that there is no duality of interest associated with this manuscript.

Open Access This article is distributed under the terms of the Creative Commons Attribution Noncommercial License which permits any noncommercial use, distribution, and reproduction in any medium, provided the original author(s) and source are credited.

\section{References}

1. Schalkwijk CG, Stehouwer CD (2005) Vascular complications in diabetes mellitus: the role of endothelial dysfunction. Clin Sci (Lond) 109:143-159

2. Steinberg HO, Chaker H, Leaming R, Johnson A, Brechtel G, Baron AD (1996) Obesity/insulin resistance is associated with endothelial dysfunction. Implications for the syndrome of insulin resistance. J Clin Invest 97:2601-2610

3. Makimattila S, Virkamaki A, Groop PH et al (1996) Chronic hyperglycemia impairs endothelial function and insulin sensitivity via different mechanisms in insulin-dependent diabetes mellitus. Circulation 94:1276-1282

4. Diederich D, Skopec J, Diederich A, Dai FX (1994) Endothelial dysfunction in mesenteric resistance arteries of diabetic rats: role of free radicals. Am J Physiol 266:H1153-H1161

5. Pflueger AC, Osswald H, Knox FG (1999) Adenosine-induced renal vasoconstriction in diabetes mellitus rats: role of nitric oxide. Am J Physiol 276:F340-F346

6. Brownlee M (2001) Biochemistry and molecular cell biology of diabetic complications. Nature 414:813-820

7. Ono Y, Aoki S, Ohnishi K, Yasuda T, Kawano K, Tsukada Y (1998) Increased serum levels of advanced glycation end products in NIDDM patients with diabetic complications. Diabetes Care 21:1027

8. Hammes HP, Brownlee M, Lin J, Schleicher E, Bretzel RG (1999) Diabetic retinopathy risk correlates with intracellular concentrations of the glycoxidation product Nepsilon-(carboxymethyl) lysine independently of glycohaemoglobin concentrations. Diabetologia 42:603-607

9. Kilhovd BK, Berg TJ, Birkeland KI, Thorsby P, Hanssen KF (1999) Serum levels of advanced glycation end products are increased in patients with type 2 diabetes and coronary heart disease. Diabetes Care 22:1543-1548

10. Tan KC, Chow WS, Ai VH, Metz C, Bucala R, Lam KS (2002) Advanced glycation end products and endothelial dysfunction in type 2 diabetes. Diabetes Care 25:1055-1059
11. Xu B, Chibber R, Ruggiero D, Kohner E, Ritter J, Ferro A (2003) Impairment of vascular endothelial nitric oxide synthase activity by advanced glycation end products. FASEB J 17:1289-1291

12. Beisswenger PJ, Howell SK, Nelson RG, Mauer M, Szwergold BS (2003) Alpha-oxoaldehyde metabolism and diabetic complications. Biochem Soc Trans 31:1358-1363

13. Shinohara M, Thornalley PJ, Giardino I et al (1998) Overexpression of glyoxalase-I in bovine endothelial cells inhibits intracellular advanced glycation endproduct formation and prevents hyperglycemia-induced increases in macromolecular endocytosis. J Clin Invest 101:1142-1147

14. Thornalley PJ (2003) Glyoxalase I-structure, function and a critical role in the enzymatic defence against glycation. Biochem Soc Trans 31:1343-1348

15. Oya T, Hattori N, Mizuno Y et al (1999) Methylglyoxal modification of protein. Chemical and immunochemical characterization of methylglyoxal-arginine adducts. J Biol Chem 274:18492-18502

16. Ahmed N, Thornalley PJ (2002) Chromatographic assay of glycation adducts in human serum albumin glycated in vitro by derivatization with 6-aminoquinolyl- $N$-hydroxysuccinimidylcarbamate and intrinsic fluorescence. Biochem J 364:15-24

17. McLellan AC, Thornalley PJ, Benn J, Sonksen PH (1994) Glyoxalase system in clinical diabetes mellitus and correlation with diabetic complications. Clin Sci (Lond) 87:21-29

18. Schalkwijk CG, van Bezu J, van der Schors RC, Uchida K, Stehouwer CD, van Hinsbergh VW (2006) Heat-shock protein 27 is a major methylglyoxal-modified protein in endothelial cells. FEBS Lett 580:1565-1570

19. Mostafa AA, Randell EW, Vasdev SC et al (2007) Plasma protein advanced glycation end products, carboxymethyl cysteine, and carboxyethyl cysteine, are elevated and related to nephropathy in patients with diabetes. Mol Cell Biochem 302:35-42

20. Fosmark DS, Torjesen PA, Kilhovd BK et al (2006) Increased serum levels of the specific advanced glycation end product methylglyoxal-derived hydroimidazolone are associated with retinopathy in patients with type 2 diabetes mellitus. Metabolism $55: 232-236$

21. Wang X, Chang T, Jiang B, Desai K, Wu L (2007) Attenuation of hypertension development by aminoguanidine in spontaneously hypertensive rats: role of methylglyoxal. Am J Hypertens 20:629636

22. Wang X, Desai K, Chang T, Wu L (2005) Vascular methylglyoxal metabolism and the development of hypertension. J Hypertens 23:1565-1573

23. Wang X, Desai K, Clausen JT, Wu L (2004) Increased methylglyoxal and advanced glycation end products in kidney from spontaneously hypertensive rats. Kidney Int 66:2315-2321

24. Wang X, Jia X, Chang T, Desai K, Wu L (2008) Attenuation of hypertension development by scavenging methylglyoxal in fructose-treated rats. J Hypertens 26:765-772

25. Wu L, Juurlink BH (2002) Increased methylglyoxal and oxidative stress in hypertensive rat vascular smooth muscle cells. Hypertension 39:809-814

26. Nemet I, Varga-Defterdarovic L, Turk Z (2006) Methylglyoxal in food and living organisms. Mol Nutr Food Res 50:1105-1117

27. Rosca MG, Mustata TG, Kinter MT et al (2005) Glycation of mitochondrial proteins from diabetic rat kidney is associated with excess superoxide formation. Am J Physiol Renal Physiol 289: F420-F430

28. Inagi R, Miyata T, Ueda $Y$ et al (2002) Efficient in vitro lowering of carbonyl stress by the glyoxalase system in conventional glucose peritoneal dialysis fluid. Kidney Int 62:679-687

29. Scheijen JL, van de Waarenburg MP, Stehouwer CD, Schalkwijk CG (2009) Measurement of pentosidine in human plasma protein by a single-column high-performance liquid chromatography 
method with fluorescence detection. J Chromatogr B Analyt Technol Biomed Life Sci 877:610-614

30. Fontijn R, Hop C, Brinkman HJ et al (1995) Maintenance of vascular endothelial cell-specific properties after immortalization with an amphotrophic replication-deficient retrovirus containing human papilloma virus 16 E6/E7 DNA. Exp Cell Res 216:199-207

31. McLellan AC, Phillips SA, Thornalley PJ (1993) The assay of $S$-Dlactoylglutathione in biological systems. Anal Biochem 211:37-43

32. Vriesman MF, Haenen GR, Westerveld GJ, Paquay JB, Voss HP, Bast A (1997) A method for measuring nitric oxide radical scavenging activity. Scavenging properties of sulfur-containing compounds. Pharm World Sci 19:283-286

33. Cooke JP, Dzau VJ (1997) Nitric oxide synthase: role in the genesis of vascular disease. Annu Rev Med 48:489-509

34. Taylor PD, Poston L (1994) The effect of hyperglycaemia on function of rat isolated mesenteric resistance artery. $\mathrm{Br} \mathrm{J}$ Pharmacol 113:801-808

35. Mukohda M, Yamawaki H, Nomura H, Okada M, Hara Y (2009) Methylglyoxal inhibits smooth muscle contraction in isolated blood vessels. J Pharmacol Sci 109:305-310

36. Berlanga J, Cibrian D, Guillen I et al (2005) Methylglyoxal administration induces diabetes-like microvascular changes and perturbs the healing process of cutaneous wounds. Clin Sci (Lond) 109:83-95

37. Lieuw-a-Fa ML, Schalkwijk CG, Engelse M, van Hinsbergh VW (2006) Interaction of Nepsilon(carboxymethyl)lysine- and methylglyoxal-modified albumin with endothelial cells and macrophages. Splice variants of RAGE may limit the responsiveness of human endothelial cells to AGEs. Thromb Haemost 95:320-328

38. Gao X, Zhang H, Schmidt AM, Zhang C (2008) AGE/RAGE produces endothelial dysfunction in coronary arterioles in type 2 diabetic mice. Am J Physiol Heart Circ Physiol 295:H491-H498

39. Ceradini DJ, Yao D, Grogan RH et al (2008) Decreasing intracellular superoxide corrects defective ischemia-induced new vessel formation in diabetic mice. J Biol Chem 283:10930-10938

40. Yao D, Taguchi $T$, Matsumura $T$ et al (2007) High glucose increases angiopoietin-2 transcription in microvascular endothelial cells through methylglyoxal modification of mSin3A. J Biol Chem 282:31038-31045

41. Schlotterer A, Kukudov G, Bozorgmehr F et al (2009) C. elegans as model for the study of high glucose mediated lifespan reduction. Diabetes 58:2450-2456

42. Thornalley PJ, Battah S, Ahmed N et al (2003) Quantitative screening of advanced glycation endproducts in cellular and extracellular proteins by tandem mass spectrometry. Biochem $\mathrm{J}$ 375:581-592

43. Forbes JM, Coughlan MT, Cooper ME (2008) Oxidative stress as a major culprit in kidney disease in diabetes. Diabetes 57:14461454

44. Vincent AM, Brownlee M, Russell JW (2002) Oxidative stress and programmed cell death in diabetic neuropathy. Ann N Y Acad Sci 959:368-383

45. Su J, Lucchesi PA, Gonzalez-Villalobos RA et al (2008) Role of advanced glycation end products with oxidative stress in resistance artery dysfunction in type 2 diabetic mice. Arterioscler Thromb Vasc Biol 28:1432-1438

46. Heumuller S, Wind S, Barbosa-Sicard E et al (2008) Apocynin is not an inhibitor of vascular NADPH oxidases but an antioxidant. Hypertension 51:211-217

47. Choudhary D, Chandra D, Kale RK (1997) Influence of methylglyoxal on antioxidant enzymes and oxidative damage. Toxicol Lett 93:141-152

48. Lee HJ, Howell SK, Sanford RJ, Beisswenger PJ (2005) Methylglyoxal can modify GAPDH activity and structure. Ann N Y Acad Sci 1043:135-145

49. Bucala R, Tracey KJ, Cerami A (1991) Advanced glycosylation products quench nitric oxide and mediate defective endotheliumdependent vasodilatation in experimental diabetes. J Clin Invest $87: 432-438$

50. Liu X, Miller MJ, Joshi MS, Sadowska-Krowicka H, Clark DA, Lancaster JR Jr (1998) Diffusion-limited reaction of free nitric oxide with erythrocytes. J Biol Chem 273:18709-18713

51. Brouwers O, Teerlink T, van Bezu J, Barto R, Stehouwer C, Schalkwijk C (2007) Methylglyoxal and methylglyoxal-arginine adducts do not directly inhibit endothelial nitric oxide synthase. Ann N Y Acad Sci 1126:231-234

52. Lapolla A, Flamini R, Dalla Vedova A et al (2003) Glyoxal and methylglyoxal levels in diabetic patients: quantitative determination by a new GC/MS method. Clin Chem Lab Med 41:1166-1173

53. Lapolla A, Reitano R, Seraglia R, Sartore G, Ragazzi E, Traldi P (2005) Evaluation of advanced glycation end products and carbonyl compounds in patients with different conditions of oxidative stress. Mol Nutr Food Res 49:685-690

54. Chaplen FW, Fahl WE, Cameron DC (1998) Evidence of high levels of methylglyoxal in cultured Chinese hamster ovary cells. Proc Natl Acad Sci U S A 95:5533-5538

55. Randell EW, Vasdev S, Gill V (2005) Measurement of methylglyoxal in rat tissues by electrospray ionization mass spectrometry and liquid chromatography. J Pharmacol Toxicol Methods 51:153-157 